\title{
Effect of High Energy Electron Irradiation on Structure and Optical Properties of ZnO Films
}

\author{
D.V. Myroniuk ${ }^{a, *}$, G.V. Lashkarev ${ }^{a}$, I.I. Shtepliuk ${ }^{a}$, V.Y. Lazorenko ${ }^{a}$, \\ V.T. MAslyuK ${ }^{b}$, I.I. Timofeeva ${ }^{a}$, A.S. RomaniuK ${ }^{c}$, V.V. StrelchuK ${ }^{c}$, O.F. Kolomys ${ }^{c}$ \\ AND V.V. KHOMYAK ${ }^{d}$
}

${ }^{a}$ Frantsevich Institute for Problems of Material Science, NAS of Ukraine, 3 Krzhizhanivsky Str., 03680 Kyiv, Ukraine

${ }^{b}$ Institute of Electron Physics, NAS of Ukraine, 21 Universitetska Str., 88017 Uzhgorod, Ukraine

${ }^{c}$ Lashkaryov Institute of Semiconductor Physics, NAS of Ukraine, 41 pr. Nauki, 03028 Kyiv, Ukraine

${ }^{d}$ Fedkovich Chernivtsi National University, 2 Kotsubinsky Str., 58012 Chernivtsi, Ukraine

\begin{abstract}
Zinc oxide films were grown on sapphire substrates by direct current magnetron sputtering and irradiated by electrons with energy $10 \mathrm{MeV}$ and fluences $10^{16}$ and $2 \times 10^{16} \mathrm{~cm}^{-2}$. As-grown and irradiated samples were investigated by $\mathrm{X}$-ray diffraction and photoluminescence spectroscopy. It was found that radiation causes the appearance of complex defects, reducing the size of coherent scattering regions and the increase of the defect PL band.
\end{abstract}

DOI: 10.12693 /APhysPolA.124.891

PACS: $61.80 .-\mathrm{x}, 78.55 . \mathrm{Et}, 71.55 . \mathrm{Gs}$

\section{Introduction}

Zinc oxide is used as active component of heterojunction and electrode for thin film solar cells [1], piezoelectric transducers, transparent conductive films [2], light emission diodes [3] etc. The benefits of zinc oxide are low cost, large reserves of natural materials and high radiation resistance [4]. The latter makes $\mathrm{ZnO}$ one of the most promising materials suitable for use in high background radiation, for example, in outer space. For space-based applications, especially those in nearearth orbit, it is important to have radiation-resistant materials. In particular, the Van Allen belt contains high fluxes of electrons (0-10 MeV) and protons (10 MeV) [5].

Although high-quality bulk $\mathrm{ZnO}$ substrates are now under development, their high cost and limited availability currently preclude their use in mass production environments. Sapphire, on the other hand, is a relatively inexpensive substrate material and well suited for future production needs due to its low cost and high-crystalline perfection. $\mathrm{ZnO}$ can also be grown on sapphire epitaxially and with a high degree of surface flatness, an essential attribute for fabrication of devices [6].

Thus, the studies of changing a structure and optical properties in the radiation environment are important for space applications of devices based on $\mathrm{ZnO}$. In this work, we report structural and optical properties of as-grown and electron irradiated $\mathrm{ZnO}$ films produced by direct current (DC) magnetron sputtering on sapphire substrates.

\section{Experimental details}

The $\mathrm{ZnO}$ films were deposited on $\mathrm{Al}_{2} \mathrm{O}_{3}$ (001) substrates at the temperature of $250^{\circ} \mathrm{C}$ by direct current

\footnotetext{
*corresponding author; e-mail: denysmyroniuk@gmail.com
}

magnetron sputtering. A disc of zinc $(100 \mathrm{~mm}$ in a diameter) with a purity of $99.99 \%$ was used as a target. High purity argon and oxygen gases were used as the sputtering and the reactive gas, respectively. The target-to-substrate distance was $40 \mathrm{~mm}$. The chamber was pumped to a base pressure of $1 \times 10^{-4} \mathrm{~Pa}$ before deposition. The films were grown in the ambient with $\mathrm{Ar} / \mathrm{O}_{2}$ ratio of 4:1. The dc power was maintained at $100 \mathrm{~W}$. The deposition time was $90 \mathrm{~min}$ for all samples. The films were irradiated with $10 \mathrm{MeV}$ electrons using the microtron electron accelerator M-30 at Institute of Electron Physics, NAS of Ukraine, Uzhgorod. The films were irradiated with the fluences of $10^{16}$ and $2 \times 10^{16}$ ions $/ \mathrm{cm}^{2}$. During irradiation the samples were cooled by nitrogen vapor to $-10^{\circ} \mathrm{C}$ which controlled by copperconstantan thermocouple. The crystal structure of samples was studied by the X-ray diffraction (XRD) analysis where the $\mathrm{Cu} K_{\alpha_{1}}$ radiation was used as a source $(\lambda=0.154056 \mathrm{~nm})$. The XRD measurements were carried out by the DRON-4 Powder Diffraction system; a scan rate of $1^{\circ} / \mathrm{min}$ and a step size of $0.01^{\circ}$ were used. It is important to note that the analyzed surface is about $\approx 1 \mathrm{~cm}^{2}$ and the penetration depth of X-rays at 20 $40 \mathrm{keV}$ is a few $\mu \mathrm{m}$. Measurement error of the peak position is about $\pm 0.01^{\circ}(2 \theta)$. Error of the $c$-lattice period determination is about $\pm 0.0003 \mathrm{~nm}$. The relative error in full width at half maximum (FWHM) calculations has been estimated to be $\pm 2 \%$. Room temperature photoluminescence (PL) spectra were measured with a Jobin-Yvon T64000 spectrometer equipped with a CCD detector, in a back scattering geometry, using the $325 \mathrm{~nm}$ excitation line of a $\mathrm{He}-\mathrm{Cd}$ laser with an incident power of $10 \mathrm{~mW}$.

\section{Results and discussion}

Figure 1 illustrates the $\theta-2 \theta$ XRD patterns of $\mathrm{ZnO}$ as-grown and irradiated films. They reveal a strong tex- 


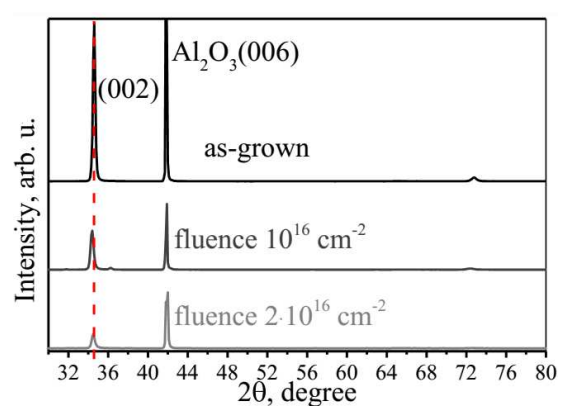

Fig. 1. XRD patterns of as-grown and electron irradiated $\mathrm{ZnO}$ films substrates.

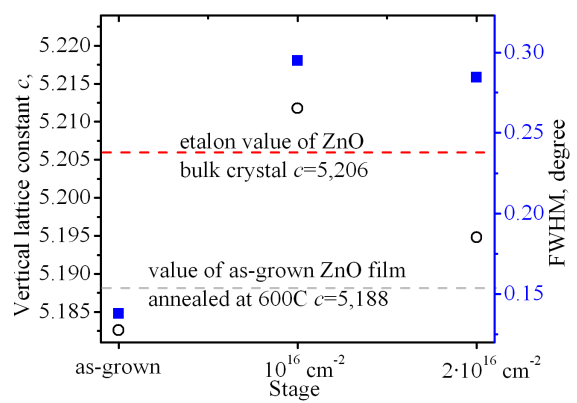

Fig. 2. The $c$ lattice periods and FWHM values for (002) reflection of $\mathrm{ZnO}$ films.

turing along the [002] axis of wurtzite, lattice being the preferential orientation of films [7]. Other $\mathrm{ZnO}$ reflexes were absent in the full pattern. The reflex $\approx 41.5^{\circ}$ relates to (006) plane of sapphire substrate.

In order to get more information about the electron irradiation effect on crystal structure, the values of lattice period $c$ were calculated before and after the each irradiation. The $c$-lattice period was calculated from the Bragg equation as following [8]:

$$
c=\frac{\lambda}{\sin \theta_{002}} .
$$

Results are shown in Fig. 2.

Several factors affect the $c$ value: (a) the lattice mismatch between sapphire substrate and $\mathrm{ZnO}$ film and (b) the difference between their coefficients of thermal expansion (CTE). The strain in films, which accumulates during film growth, often causes significant deterioration in terms of surface morphology, optical, and structural properties. Hence, the residual strain should itself be considered precisely to assess physical properties of the strained film.

The $c$ surface of sapphire is composed of alternate layers of (sixfold symmetric) oxygen and (threefold symmetric) $\mathrm{Al}$ atoms, while in the wurtzite structure of $\mathrm{ZnO}$, both $\mathrm{O}$ and $\mathrm{Zn}$ are sixfold symmetric about the $\mathrm{ZnO} c$ axis. In idealized case $\mathrm{ZnO}$ oxygen atoms would bond to the underlying sapphire $\mathrm{Al}$ atoms to form a structure (Fig. 3a) with a mismatch of $31.8 \%$ [6]. It is possible when the diffusion of atoms on the surface is suppressed

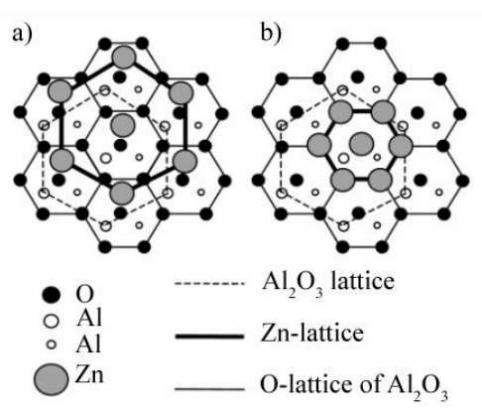

Fig. 3. Schematic diagram showing the epitaxial relationship of $\mathrm{ZnO}(001)$ grown on $\mathrm{Al}_{2} \mathrm{O}_{3}(001)$ [6].

at low growth temperatures. However, when the growth temperature is high, the kinetic energy of zinc atoms becomes high, and it is expected that the zinc atoms will become more diffused on the substrate surface. These effects cause zinc atoms to select sites having smaller lattice mismatch. In this case, a zinc atom is bounded to one oxygen atom in $\mathrm{Al}_{2} \mathrm{O}_{3}$, and a tetrahedral coordination of $\mathrm{ZnO}$ can be formed by supplying three other oxygen atoms. The relationships between the orientation of $\mathrm{ZnO}$ and substrate unit cells are $30^{\circ}$-twist (Fig. 3b). The oxygen sublattice has a lattice period of $2.75 \AA$, and the lattice mismatch to $\mathrm{ZnO}$ is $-18.2 \%$ (compressive) [9].

It is worth to note that another strain due to CTE mismatch should be considered, especially for heteroepitaxy. Since there is a large difference between the growth and measurement temperatures, the CTE mismatch should have a large influence on lattice strain. As mentioned before, the strain due to CTE mismatch is revealed to be tensile (see CTE data for both $\mathrm{Al}_{2} \mathrm{O}_{3}$ and $\mathrm{ZnO}[10]$ ).

As-grown film has the smaller $c$ period $(5.183 \AA)$ than that of the $\mathrm{ZnO}$ bulk ( $5.206 \AA$ ), indicating the existence of a compressive stress along the $c$-axis or a tensile biaxial strain in the growth plane perpendicular to the $c$-axis. This tensile strain can be easily understood from the growth model given in Fig. 3a and considerations above. The existence of the strain also demonstrates that the film was being grown while keeping the epitaxial relationship with the substrate, which is an evidence of two-dimensional (2D) epitaxial growth [9].

After irradiation it was found that intensity and $c$ value changed (Fig. 1, Fig. 2). In our case, there are several reasons, induced by electron irradiation, that may affect the (002) peak position and consequently lattice parameters: (i) electron-nucleus collisions which create defects and lead to swelling of the crystal lattice, (ii) electronelectron collisions lead to heating, i.e. radiation annealing and relaxation of the lattice. These factors are interrelated and counteracted between each other. Most of the energy losses in high-energy electron bombardment occur from electron-electron, rather than electron-nucleus, collisions [11]. Although the samples were cooled in nitrogen vapor, such e-e collisions lead to heating the microcrystals. 
It was found that the electron irradiation by fluence $10^{16} \mathrm{~cm}^{-2}$ leads to the enlargement of the $c$-lattice parameter of $\mathrm{ZnO}$ film. It can be explained by creating defects. The increasing fluence to $2 \times 10^{16} \mathrm{~cm}^{-2}$ causes the balance between the formation of defects and their annealing. As a result, the lattice of microcrystals can be relaxed (Fig. 2). This process also is reflected in the change of the FWHM values of corresponding reflexes (Fig. 2): irradiation by fluence $10^{16} \mathrm{~cm}^{-2}$ results in enhance of the FWHM, whereas fluence of $2 \times 10^{16} \mathrm{~cm}^{-2}$ bring a slight decrease in the FWHM. The intensity of the (002) reflection keeps decreasing when the irradiation fluence increases.

The room temperature PL measurements were carried out to examine distribution of various emission levels observed in as-grown and irradiated with different fluences $\mathrm{ZnO}$ films, as shown in Fig. 4). The as-grown sample showed the intense near band edge (NBE) emission in ultraviolet $(\mathrm{UV})$ region $(\approx 3.24 \mathrm{eV})$ and weak deep-level emission orange region $(\approx 2.1 \mathrm{eV})$; whereas, irradiated samples showed weaker UV emission and intense broad peak in orange-red $(\approx 2 \mathrm{eV})$ region.

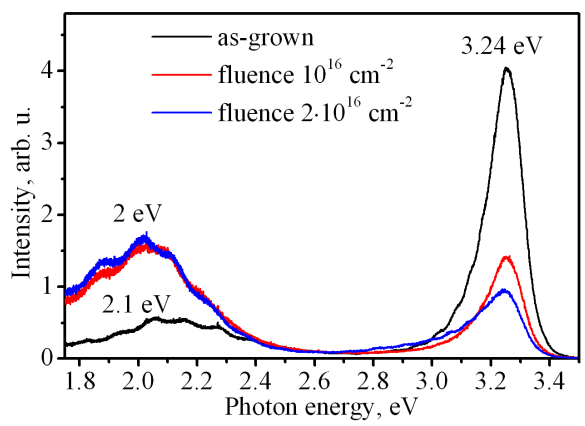

Fig. 4. PL spectra of as-grown and electron irradiated $\mathrm{ZnO}$ films substrates.

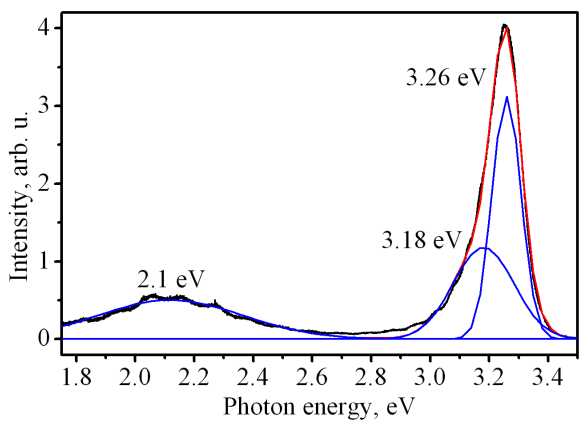

Fig. 5. Deconvolution of PL spectra of as-grown $\mathrm{ZnO}$ film.

The UV emission observed in as-grown $\mathrm{ZnO}$ films consists of intense band edge emission with a maximum at $\approx 3.26 \mathrm{eV}$ and violet peak at $\approx 3.18 \mathrm{eV}$ (Fig. 5). The first one is due to radiative recombination of localized excitons bound to neutral donor and/or acceptor [12]. Energy position of the PL band for unirradiated $\mathrm{ZnO}$ films shifted to low energy side by $100 \mathrm{meV}$ in comparison with single-crystal zinc oxide (3.37 eV at $300 \mathrm{~K}$ [13]) due to elastic tensile strains. Against the background of the defect PL band recorded interference lines associated with the multiple reflection of radiation from the interface between film and substrate. The $3.18 \mathrm{eV}$ peak in the violet region is due to band transition from the zinc interstitial $\left(\mathrm{Zn}_{\mathrm{I}}\right)$ level to the valence band.

The NBE emissions were relatively broad due to overlap of the transitions corresponding to the free excitons as well as the excitons bound to neutral donors and acceptors. The deep level emission (DLE) in the orange-red region $(2.1 \mathrm{eV})$ assigns to electronic transition between conduction band and deep acceptor oxygen interstitial $\left(\mathrm{O}_{\mathrm{I}}\right)$ [14]. The orange-red emission from $\mathrm{ZnO}$ layers was explained by full potential linear muffin-tin orbital method, which suggested that the position of $\mathrm{O}_{\mathrm{I}}$ level is located at $2.28 \mathrm{eV}$ below the conduction band [15]. The broad width can be explained by set of transitions from conductive band and $\mathrm{Zn}_{\mathrm{I}}$ level to $\mathrm{O}_{\mathrm{I}}$ level.

After first step irradiation (fluence $10^{16} \mathrm{~cm}^{-2}$ ) it clearly can be seen decreasing of NBE emission and arise of the DLE with center at $\approx 2 \mathrm{eV}$ arises (Fig. 6). The intensity of UV luminescence $(3.26 \mathrm{eV})$ decreases, which may be associated with an increase in density of the defect playing role of nonradiative recombination centers. Earlier, Look et al. have shown that electron irradiation with energy more than $1.6 \mathrm{MeV}$ causes to create complex defects, which consist of the multiple displacements [11]. They proposed the idea of multiple displacements along a chain of atoms in $\mathrm{ZnO}$. It was supposed that the electron energy is just high enough to displace a $\mathrm{Zn}$ atom. If the initial energy is higher (more than $1.6 \mathrm{MeV}$ in our case), then the collision may give the $\mathrm{Zn}$ atom enough kinetic energy to knock out the $\mathrm{O}$ atom directly below it. This process can go on. Then the $\mathrm{O}$ atom can knock out the Zn below it, etc. At some point, the last knocked out $\mathrm{Zn}_{\mathrm{I}}$ will be far enough from the parent $\mathrm{V}_{\mathrm{Zn}}$ to avoid immediate recombination. On the other hand, the simple $\mathrm{V}_{\mathrm{Zn}}-\mathrm{Zn}_{\mathrm{I}}$ (where $\mathrm{V}_{\mathrm{Zn}}$ is zinc vacancy) Frenkel pair would be unstable, because the positively charged $\mathrm{Zn}_{\mathrm{I}}$ must be more than a nearest neighbor distance away from the negatively charged $\mathrm{V}_{\mathrm{Zn}}$ to avoid immediate recombination. If the chain defect suggested above is accurate, then an acceptor might be $\mathrm{V}_{\mathrm{Zn}}-\mathrm{Zn}_{\mathrm{O}}-\mathrm{O}_{\mathrm{Zn}}$ (where $\mathrm{Zn}_{\mathrm{O}}$ is zinc antisite and $\mathrm{O}_{\mathrm{Zn}}$ is antisite of oxygen) and the donor, $\mathrm{Zn}_{\mathrm{I}}$.

A similar situation arises if the oxygen atoms were hit by the electrons. The complicated triple centre that contained associated $\mathrm{V}_{\mathrm{Zn}}-\mathrm{Zn}_{\mathrm{O}}-\mathrm{O}_{\mathrm{Zn}}$ may be responsible for DLE band at $1.85 \mathrm{eV}[16]$ (Fig. 4). Other DLE band at $2.2 \mathrm{eV}$ can be associated with another acceptor defect complex, such as $\mathrm{V}_{\mathrm{O}}-\mathrm{O}_{\mathrm{Zn}}$ (where $\mathrm{V}_{\mathrm{O}}$ is oxygen vacancy) [17]. The increase in intensity at $2 \mathrm{eV}$ indicates enhancement of the concentration of acceptor defects such as oxygen. At the same time, the low intensity of the $\mathrm{Zn}_{\mathrm{I}^{-}}$ -related to emission band at $3.18 \mathrm{eV}$ is caused by donor-acceptor pairs (DAP) transitions and relatively broad the DLE peaks are due to overlap of the emissions bands 
related to transitions corresponding to the free excitons and $\mathrm{Zn}_{\mathrm{I}}$ at room temperature [14, 18]. Indeed, radiative centres in $n$-type semiconductors are more likely acceptor-type defects.

In II-VI compounds, such as CdS, CdSe, ZnS and ZnSe centre responsible for self-activated emission was shown to be cation vacancy or DAP consisting of cation vacancy and shallow donor [19] and more complicated center that contained associated DAP and more distant donor was found [20].

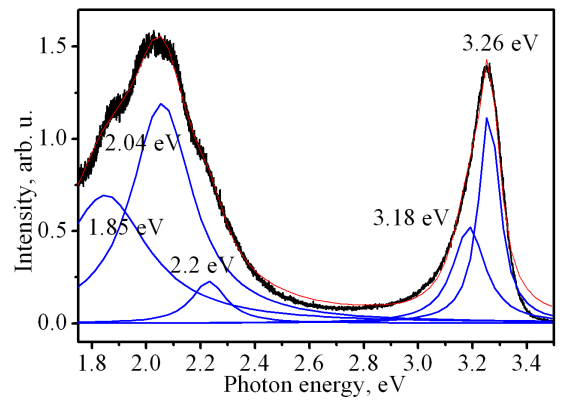

Fig. 6. Deconvolution of PL spectra of irradiated by fluence $10^{16} \mathrm{~cm}^{-2} \mathrm{ZnO}$ film.

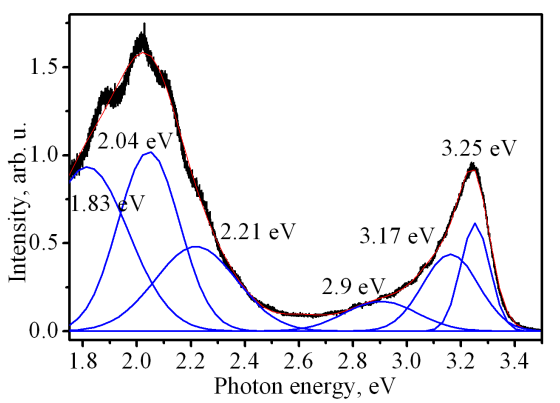

Fig. 7. Deconvolution of PL spectra of irradiated by fluence $2 \times 10^{16} \mathrm{~cm}^{-2} \mathrm{ZnO}$ film.

The proposed model is also confirmed by the absence of green $(\approx 2.47 \mathrm{eV})$ and blue $(\approx 2.9 \mathrm{eV})$ emission regions corresponding to oxygen $[14,21]$ and zinc vacancies [14], respectively. Thus mentioned form complexes with antisite defects. Figure 7 shows the deconvoluted PL spectra $\mathrm{ZnO}$ film irradiated by electrons with the $2 \times 10^{16} \mathrm{~cm}^{-2}$ fluence. It is found further the decrease of NBE emission intensity and observed certain redistribution of peak intensities compared to the above results. In addition, there was revealed the appearance of the small shoulder of the peak at $2.9 \mathrm{eV}$ which corresponded to transitions from conduction band and shallow donor level of $\mathrm{Zn}_{\mathrm{I}}$ to acceptor level of $\mathrm{V}_{\mathrm{Zn}}$.

\section{Conclusions}

In summary, we have studied the effect of high energy electron irradiation on the structure and optical properties of $\mathrm{ZnO}$ thin films, grown by the dc magnetron sput- tering. It was revealed that such type of irradiation significantly affects the structure, resulting in creation of the complex defects and radiation annealing. These findings were revealed from the analysis of the XRD and PL spectra. Furthermore, at the high irradiation fluences the films retain their lattice structure. Therefore, these films can be used in the optoelectronics devices in a high radiation background.

\section{References}

[1] W. Septina, S. Ikeda, T. Harada, M. Matsumura, Phys. Status Solidi C 1, (2013).

[2] D.R. Sahu, S.-Y. Lin, J.-L. Huang, Appl. Surf. Sci. 252, 7509 (2006).

[3] G.V. Lashkarev, V.A. Karpyna, V.I. Lazorenko, A.I. Ievtushenko, I.I. Shtepliuk, V.D. Khranovskyy, Low Temp. Phys. 37, 226 (2011).

[4] D.C. Look, Mater. Sci. Eng. B 80, 383 (2001).

[5] D.C. Look, D.C. Reynolds, J.W. Hemsky, Appl. Phys. Lett. 75, 6 (1999).

[6] P. Fons, K. Iwata, A. Yamada, K. Matsubara, S. Niki, K. Nakahara, T. Tanabe, H. Takasu, Appl. Phys. Lett. 77, 1801 (2000).

[7] N. Fujimura, T. Nishihara, S. Goto, J. Xu, T. Ito, J. Cryst. Growth 130, 269 (1993).

[8] B.D. Cullity, Wlements of X-ray Diffraction, Addison-Wesley, 1956, p. 371.

[9] B.P. Zhang, K. Wakatsuki, N.T. Binh, N. Usami, Y. Segawa, Thin Solid Films 449, 12 (2004).

[10] S.H. Park, T. Hanada, D.C. Oh, T. Minegishi, H. Goto, G. Fujimoto, J.S. Park, I.H. Im, J.H. Chang, M.W. Cho, T. Yao, K. Inaba, Appl. Phys. Lett. 91, 231904 (2007).

[11] D.C. Look, J.W. Hemsky, J.R. Sizelove, Phys. Rev. Lett. 82, 2552 (1999).

[12] Y.W. Chen, Y.C. Liu, S.X. Lu, et al., J. Chem. Phys. 123, 134701 (2005).

[13] Ü. Özgür, Ya.I. Alivov, C. Liu, A. Teke, M.A. Reshchikov, S. Doğan, V. Avrutin, S.-J. Cho, H. Morkoç, J. Appl. Phys. 98, 041301 (2005).

[14] C.H. Ahn, Y.Y. Kim, D.C. Kim, S.K. Mohanta, H.K. Cho, J. Appl. Phys. 105, 013502 (2009).

[15] X.L. Wu, G.G. Siu, C.L. Fu, H.C. Ong, Appl. Phys. Lett. 78, 2285 (2001).

[16] F. Tuomisto, K. Saarinen, D.C. Look, G.C. Farlow, Phys. Rev. B 72, 085206 (2005).

[17] B. Lin, Z. Fu, Y. Jia, Appl. Phys. Lett. 79, 943 (2001).

[18] N.O. Korsunska, L.V. Borkovska, B.M. Bulakh, L.Yu. Khomenkova, V.I. Kushnirenko, I.V. Markevich, J. Lumin. 102-103, 733 (2003).

[19] G.D. Watkins, Solid State Commun. 12, 589 (1973).

[20] J.R. James, J.E. Nicholls, B.C. Cavenett, J.J. Davies, D.J. Dunstan, Solid State Commun. 17, 969 (1975).

[21] F.H. Leiter, H.R. Alves, A. Hofstaetter, D.M. Hoffmann, B.K. Meyer, Phys. Status Solidi B 226, R4 (2001). 